\title{
Development of Subcellular mRNA Compartmentation in Hippocampal Neurons in Culture
}

\author{
Robin Kleiman, ${ }^{1,2, a}$ Gary Banker, ${ }^{1}$ and Oswald Steward ${ }^{1}$ \\ 'Department of Neuroscience and ${ }^{2} T$ he Neuroscience Graduate Program, University of Virginia Health Sciences Center, \\ Charlottesville, Virginia 22908
}

\begin{abstract}
Neurons possess an RNA transport system that is present in dendrites (but not axons) and sort mRNAs so that some mRNAs are restricted to cell bodies while a few others (like the mRNA for MAP2) are present in dendrites. The present study evaluates when dendrite-specific RNA transport and mRNA sorting into cell body and somatodendritic compartments first appear in developing hippocampal neurons maintained in culture. ${ }^{3}{ }^{3} \mathrm{H}$-uridine pulse-chase paradigm was used to evaluate transport of newly synthesized RNA from the site of synthesis in the nucleus into the developing neurites. The intracellular distribution of mRNAs encoding actin, tubulin, GAP-43, and MAP2 as well as polyA RNA and rRNA was evaluated by in situ hybridization at different stages of development. Newly synthesized RNA was translocated into both developing axons and dendrites early in development, but only into dendrites as the neurons matured. Tubulin, GAP-43, and actin mRNAs, which are restricted to cell bodies in mature neurons, were found exclusively in neuronal cell bodies at all developmental stages. MAP2 mRNA, which is present in the dendrites of mature neurons, was present at very low levels in neurons at $\mathbf{2}$ or $\mathbf{3} \mathbf{d}$ in culture and was not detectable within dendrites. The overall levels of MAP2 mRNA increased over time, and by 5-7 d in culture, MAP2 mRNA was detectable in some dendrites. PolyA RNA and rRNA were detectable in developing neurites including axons. Levels of polyA and rRNA increased in dendrites as neurons matured while labeling of axons diminished. By $10 \mathrm{~d}$ in culture, axonal labeling for polyA and rRNA had virtually disappeared. The increase in the levels of polyA, rRNA, and MAP2 mRNA in dendrites between 5 and $7 \mathrm{~d}$ in culture corresponds roughly with the appearance of other dendritic characteristics and the beginning of dendritic outgrowth.
\end{abstract}

[Key words: RNA, in situ hybridization, development, dendritic transport, polarity, MAP2]

\footnotetext{
Received March 16, 1993; revised Aug. 4, 1993; accepted Aug. 10, 1993

We thank the following people for the gifts of the cDNA clones used to generate cRNA probes in these experiments: Drs. A. Matus (MAP2), A. Routtenberg (GAP43), and M. Kirschner (actin and tubulin). We thank Hannelore Asmussen and Leanna Whitmore for excellent technical assistance. The data in this article were included in a dissertation submitted by R.K. in partial fulfillment of the requirements for the Ph.D. R.K. was a predoctoral trainee on NIH HD07323. This work was supportcd by NIH NS23094.

Correspondence should be addressed to Oswald Steward, Box 5148 MR4 Annex, University of Vitginia School of Medicine, Charlottesville, VA 22908.

a Present address: Department of Physiology, University of California School of Medicine, San Francisco, CA 94143.

Copyright (C) 1994 Society for Neuroscience $0270-6474 / 94 / 141130-11 \$ 05.00 / 0$
}

An important characteristic of the dendrites of CNS neurons is that they possess the capability for local synthesis of particular proteins (for a review, see Steward and Banker, 1992). By contrast, most mature axons normally have little or no capability for local macromolecular synthesis throughout most of their length.

A variety of evidence hints at the functional significance of dendritic protein synthesis. For example, most of the polyribosomes within dendrites are selectively localized beneath synaptic sites (Steward and Levy, 1982). These polyribosomes are particularly prominent during periods of synapse growth (Steward and Falk, 1986). Biochemical studies of proteins synthesized within isolated "synaptodendrosomes" indicate that the polyribosomes synthesize certain as yet unidentified components of the synaptic junction (Rao and Steward, 1991). Studies of the migration of newly synthesized RNA indicate that dendrites also possess a mechanism for transporting RNA that is not present in the axons of relatively mature neurons (Davis et al., 1987, 1990).

The mRNAs that have so far been identified within dendrites include the mRNA for MAP2, a dendrite-specific cytoskeletal protein (Garner et al., 1988), and the $\alpha$ subunit of calcium/ calmodulin-dependent protein kinase II, a major component of the postsynaptic membrane specialization (Burgin et al., 1990). Most other mRNAs whose subcellular distributions have been evaluated are detectable only in neuronal cell bodies and proximal dendrites. The most convincing evidence in support of this conclusion comes from studies of mRNA distribution in neurons in culture. In situ hybridization studies have revealed that the mRNAs encoding cytoskeletal proteins (actin, tubulin, and neurofilament protein), GAP-43 (a membrane-associated phosphoprotein), and glutamate receptors can be detected only in cell bodies or, in some cases, very proximal dendrites (Bruckenstein et al., 1990; Kleiman ct al., 1990; Craig ct al., 1993). In contrast, MAP2 mRNA is present at relatively high levels in dendrites (Bruckenstein et al., 1990; Kleiman et al., 1990), and poly $\mathrm{A}^{+}$RNA and ribosomal RNA can be found throughout the dendrites of neurons in culture (Kleiman et al., in press). One study has reported the presence of the mRNA for amyloid precursor protein (APP) in the dendrites of neurons in culture (Strong et al., 1990). Studies of APP mRNA distribution in tissue sections do not suggest a dendritic localization, however (Higgins et al., 1988; Lewis et al., 1988). There is also evidence that a nonmessenger RNA termed $\mathrm{BC} 1$ is present in dendrites (Tiedge et al., 1991a,b). This RNA is a polymerase III transcript of unknown function. Taken together, these observations suggest that the mechanisms allowing RNA transport and the targeting 
of particular mRNAs into dendrites, which together create the capacity for local synthesis of particular proteins, play a key role in establishing the molecular domains that allow dendrites to function as they do.

Given the fact that RNA sorting and transport mechanisms are such prominent features of dendrites, we wished to determine when these capabilities first appeared during neuronal differentiation. Studies of hippocampal pyramidal cells developing in low-density cultures have suggested that neurons initially develop undifferentiated neurites (referred to as minor processes) that do not have the characteristics of either axons or dendrites (Dotti et al., 1988). Cells at this stage are said to be at developmental stage 2 . Beginning at about $1-2 \mathrm{~d}$ in culture, one neurite begins to grow at a rate that is much faster than the others; this neurite becomes the axon (developmental stage 3). At about $4 \mathrm{~d}$ in culture, the other processes begin to exhibit characteristics of dendrites; in particular, they begin to stain heavily for the dendrite-specific microtubule-associated protein MAP2. Synapses also begin to form at about this time. These developmental studies indicate that a number of maturational changes occur in developing dendrites beginning after $4 \mathrm{~d}$ in vitro that reflect the emergence of their functional characteristics as receptive elements.

The overall objective in the present study was to determine whether the development of RNA sorting and transport mechanisms occurred concurrently with, preceded, or followed the emergence of other dendritic characteristics. The specific goals were (1) to determine when dendritic transport of newly synthesized RNA is first detectable in neurons developing in culture, (2) to determine when rRNA, polyA RNA, and the dendritic mRNA MAP2 first appear in developing dendrites, (3) to determine whether mRNAs that are confined to the cell body in mature neurons are also restricted to the cell body at all developmental stages (implying the existence of sorting mechanisms early in development), and (4) to determine whether RNA transport mechanisms or any RNA is present in developing axons.

\section{Materials and Methods}

Cell culture. Cultures of hippocampal neurons were prepared as described previously (Banker and Cowan, 1977; Goslin and Banker, 1991). Briefly, hippocampi from embryonic day 18-19 rat fetuses were collected and incubated in $0.25 \%$ trypsin for $15 \mathrm{~min}$ at $37^{\circ} \mathrm{C}$. Neurons were dispersed by trituration and plated onto polylysine-treated glass coverslips ("Assistent" brand, Carolina Biological Supply Co.) at a density of 50,000 cells per $60 \mathrm{~mm}$ dish. After the neurons had attached, the coverslips were transferred to dishes containing monolayer cultures of astroglia and maintained in serum-free medium. Some cultures were treated with cytosine arabinoside $\left(5 \times 10^{-6} \mathrm{M}\right)$ on day 4 or 5 to inhibit glial proliferation.

Fixation. Neurons grown on coverslips were fixed for $10-15 \mathrm{~min}$ in $4 \%$ paraformaldehyde, $4 \%$ sucrose in PBS (warmed to $37^{\circ} \mathrm{C}$ ). Coverslips were then rinsed in PBS, transferred to $70 \%$ ethanol, and stored at $4{ }^{\circ} \mathrm{C}$ until prehybridization.

Hybridization of cultured neurons with $C R N A$ probes. The CDNA for the MAP2 probe was a gift from A. Matus (Friedrich Miescher Institut) and has been characterized previously (clone 19a; Garner et al., 1988). The chicken $\beta$-tubulin and $\beta$-actin cDNAs were gifts from M. Kirschner (Cleveland et al., 1980). The growth associated protein-43 (GAP-43) cDNA was a gift from A. Routtenberg (Northwestern Univ.) and has been described previously (Rosenthal et al., 1987). The chicken $\beta$-actin cDNA clone is complementary to the entire 2.0 kilobase $(\mathrm{kb})$ coding region. The cDNA was subcloned into pBR322. This plasmid was linearized with BamHI and transcribed with the T7 promoter to produce full-length antisense probes. The preparation of the other probes has been described previously (Kleiman et al., 1990).
The probe for polyA RNA was derived from an 80 base pair (bp) $\mathrm{A} / \mathrm{T}$ insert subcloned into the EcoRI/HindIII sites of pGem $3 \mathrm{zf}(+)$, which was a gift from R. Fremeau (Duke Univ.) (Bruckenstein et al., 1990). The insert was excised with PvuII and labeled as a cRNA probc from the T7 promoter with ${ }^{3} \mathrm{H}-\mathrm{UTP}$ (New England Nuclear, NET-380). Probes for rRNA and polyA RNA were labeled with ${ }^{3} \mathrm{H}$ rather than ${ }^{35} \mathrm{~S}$ because the short path length of ${ }^{3} \mathrm{H}$ improves resolution (Kleiman et al., in press). This is especially advantageous at early time points when neurites extend only a short distance from the cell body.

All other cRNA probes were labeled by transcription reactions in the presence of ${ }^{35}$ S-UTP, using the RNA transcription kit from Stratagene (T3 or T7). SP6 enzyme was purchased from Promega (Madison, WI). The specific activity of the antisense probes ranged from 3.1 to $5.6 \times$ $10^{8} \mathrm{cpm}$ per $\mu \mathrm{g}$ of RNA. Neurons were hybridized with cRNA probes as previously described (Kleiman et al., 1990).

Hybridization with oligonucleotide probes. To detect rRNA, we used an oligonucleotide probe complementary to a 48 base stretch of the $28 \mathrm{~S}$ ribosomal RNA subunit. The oligonucleotide was end-labeled with ${ }^{3} \mathrm{H}$-dATP $\left(2,8,5^{\prime}-{ }_{-3} \mathrm{H}[\mathrm{New}\right.$ England Nuclear, NET-591]) using terminal deoxynucleotidyl transferase (TdT; Ratliff Biochemical), in a modified version of the reaction described by Young (1989). Briefly, $78 \mathrm{ng}$ of oligonucleotide was incubated with $2 \mu \mathrm{l}$ of TdT, and $6.7 \mu \mathrm{l}$ of ${ }^{3} \mathrm{H}$-dATP in TdT tailing buffer (Bethesda Research Labs) at $37^{\circ} \mathrm{C}$ for $75 \mathrm{~min}$ (total volume of $5(\mu \mathrm{l})$. Labeled probes were extracted twice with equal volumes of phenol/chloroform (1:1) and precipitated twice in ethanol to eliminate unincorporated nucleotides. The specific activity of these probes was approximately $7-8 \times 10^{-4} \mathrm{cpm} / \mu \mathrm{l}$ for ${ }^{3} \mathrm{H}$-labeled probes. To assess specificity of the hybridization obtained with the labeled oligonucleotide prohe, control hybridizations were carried out with a random 48 mer oligonucleotide probe.

Oligonucleotide hybridization was carried out according to a modified version of the protocol outlined by Young (1989). Prior to hybridization, fixed neurons were rehydrated in two washes of PBS followed by a 10 min wash in $0.25 \%$ acetic anhydride in $0.1 \mathrm{M}$ triethanolamine $\mathrm{HCl}$. Coverslips were then serially dehydrated in ethanol, and extracted with chloroform for $10 \mathrm{~min}$. Coverslips were rinsed in $95 \%$ ethanol and air dried for $30 \mathrm{~min}$. Dry coverslips were placed cell side down in a drop of hybridization mixture (hybridization bufter contains $50 \%$ formamide, $600 \mathrm{~mm} \mathrm{NaCl}, 80 \mathrm{~mm}$ Tris- $\mathrm{HCl} \mathrm{pH} 7.5,4 \mathrm{~mm}$ EDTA, $0.1 \%$ sodium pyrophosphate, $0.2 \%$ SDS, $0.2 \mathrm{mg} / \mathrm{ml}$ sodium heparin, $10 \%$ dextran sulfate). Approximately 70,000-80,000 cpm of probe was added to 100 $\mu$ l of hybridization buffer for each coverslip. Hybridizations were carried out overnight at $38^{\circ} \mathrm{C}$. Posthybridization washes consisted of three rapid rinses in $2 \times$ saline-sodium citrate (SSC) followed by two 30 min washes, and then a $1 \mathrm{hr}$ wash in $50 \%$ formamide $/ 2 \times \mathrm{SSC}$ at $38^{\circ} \mathrm{C}$, followed by two $30 \mathrm{~min}$ washes in $0.5 \times \mathrm{SSC}$ at room temperature. Coverslips were then dehydrated and air dried before mounting on glass slides for autoradiography.

Pulse labeling of newly synthesized RNA. Pulse labeling of newly synthesized RNA was carried out according to the procedure of Davis et al. (1987). Neurons were incubated in the presence of ${ }^{3} \mathrm{H}$-uridine (40 $\mu \mathrm{Ci} / \mathrm{ml})$ for $\mathrm{l} \mathrm{hr}$, rinsed in balanced salt solution, and returned to media without labeled uridine and with an excess of unlabeled uridine $\left(10^{-4}\right.$ M). Neurons were fixed with $4 \%$ paraformaldehyde (as described above) $0,1,3$, or $6 \mathrm{hr}$ following the end of the labeling period and processed for autoradiography as described in Davis et al. (1987). Young cultures (1-3-d-old) with short processes were fixed after a 0,1 , or $3 \mathrm{hr}$ chase period. Older cultures were fixed after a 0,3 , or $6 \mathrm{hr}$ chase interval. The fixation method retains ${ }^{3} \mathrm{H}$-uridine that has been incorporated into newly synthesized RNA, but not free ${ }^{3} \mathrm{H}$-uridine (Perry, 1963; Monneron and Moule, 1966).

Autoradiography. Coverslips were dried and mounted on clean slides. Slides were dipped in Kodak NTB2 emulsion, exposed in the dark for 2-4 weeks, and developed for 3 min with Kodak D-19 at $15^{\circ} \mathrm{C}$.

Quantitative analysis. To provide a quantitative measure of the extent of dendritic and axonal labeling in the RNA transport and in situ hybridization experiments, counts were made of the number of labeled neurites per cell at each developmental stage. Slides were chosen for quantitative analysis if background labeling was low and labeling appeared to be specific (as evidenced by hybridization to only appropriate cell types present on the coverslip). The sample of neurons was obtained by making five equally spaced sweeps across one coverslip; every neuron encountered was scored for the presence of dendritic or axonal labeling. Unlabeled cells (fewer than five silver grains over the cell body) or cells with an aberrant morphology were excluded. Between 150 and 300 cells were scored for each time point with each probe. 


\section{H-Uridine pulse 3-6 hour chase}
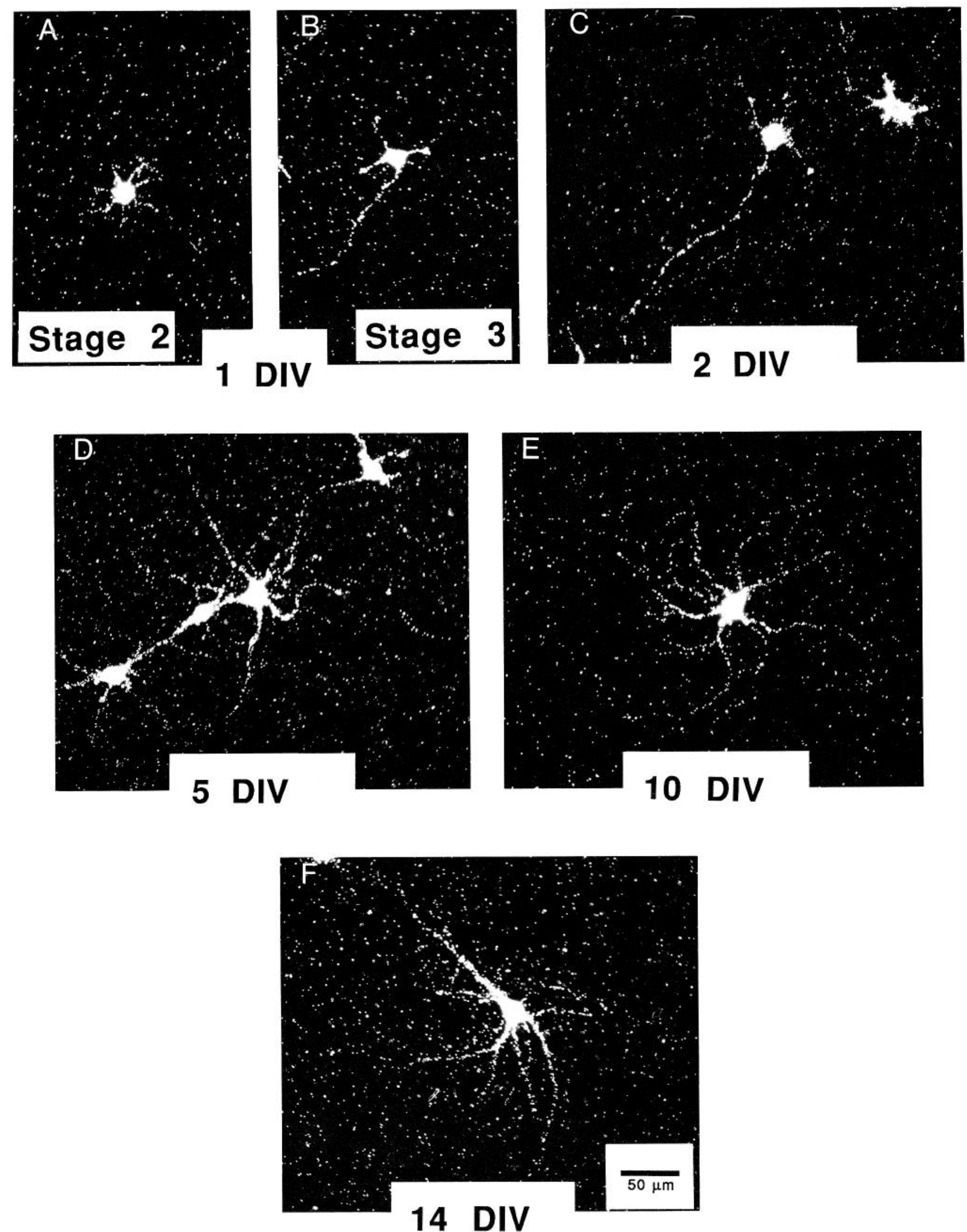


\begin{tabular}{|c|c|c|c|c|}
\hline $\begin{array}{l}\text { Days } \\
\text { in vitro }\end{array}$ & $N$ & $\begin{array}{l}\text { Two or more } \\
\text { labeled } \\
\text { dendrites }\end{array}$ & $\begin{array}{l}\text { One labeled } \\
\text { dendrite }\end{array}$ & $\begin{array}{l}\text { Nolabeled } \\
\text { dendrites }\end{array}$ \\
\hline 1 & 155 & $55 \%$ & $22 \%$ & $23 \%$ \\
\hline 3 & 248 & $86 \%$ & $9 \%$ & $5 \%$ \\
\hline 5 & 228 & $95 \%$ & $4 \%$ & $1 \%$ \\
\hline 10 & 169 & $86 \%$ & $8 \%$ & $6 \%$ \\
\hline 14 & 215 & $86 \%$ & $6 \%$ & $8 \%$ \\
\hline
\end{tabular}

Neuronal processes were identified as axons or dendrites based on previously defined morphological criteria (Bartlett and Banker, 1984; Dotti et al., 1988). Axons were considerably longer than dendrites and remained untapered and relatively unbranched (Bartlett and Banker, 1984). The presumptive axon could be identified as early as $1 \mathrm{~d}$ in culture by virtue of its length (Dotti et al., 1988) (see Fig. $3 B, D$ ). In general, the developing processes that were not the axon were considered minor processes (1-5 d in vitro) (see Fig. $3 B, D$ ) or dendrites ( 5 or more days in vitro), depending upon how long the cells had been in culture. Dendrites were thicker and their diameter tapered with distance from the cell body (Bartlett and Banker, 1984).

For neurons labeled with ${ }^{3} \mathrm{H}$-uridine, polyA RNA probes, or rRNA probes, a process with 10 or more overlying silver grains was considered labeled. Neurons were categorized based on the number of labeled dendritic or minor processes (no labeled processes, one labeled process, two or more labeled processes). Neurons hybridized with a probe for MAP2 were scored as positive for dendritic label if more than 10 silver grains were present over a single dendrite at a distance of at least one cell body diameter away from the cell soma. The extent of axonal labeling was evaluated similarly. After $3 \mathrm{~d}$ in culture, axonal labeling could not be evaluated quantitatively because axons could not be traced to their cell of origin. The significance of differences in the proportion of cells exhibiting axonal or dendritic labeling was determined according to Bruning and Kintz (1977).

\section{Results}

Appearance of newly synthesized RNA in developing neuronal processes

To evaluate whether newly synthesized RNA was translocated into neurites of developing cells, neurons were incubated in ${ }^{3} \mathrm{H}$ uridine for $1 \mathrm{hr}$ and fixed for autoradiography immediately or after a 1, 3, or $6 \mathrm{hr}$ chase period. Examples of labeling patterns in neurons at different developmental ages are presented in Figure 1. In all cases, labeling was restricted to the cell body at the end of the labeling period. After 3 and $6 \mathrm{hr}$, the labeling spread progressively from the nucleus into the neurites. The rate of translocation of labeling over time was difficult to compare in neurons of different ages because label reached the end of the short processes of 1 - and 2-d-old cells by $1 \mathrm{hr}$ after the end of the pulse. This is consistent with the rate of translocation in older neurons (Davis et al., 1987, 1990).

After $1 \mathrm{~d}$, about $30 \%$ of cells had developed axons (stage 3 of Dotti et al., 1988). The remainder were at stage 2 of development. About $55 \%$ of 1 -d-old cells exhibited labeling over two or more minor processes at the end of a $3 \mathrm{hr}$ chase period, regardless of whether they were at stage 2 or 3 (Fig. 1A). Neurons maintained in culture for $3 \mathrm{~d}$ displayed labeling patterns that

\begin{tabular}{lllll}
\hline Table 2. & Appearance of rRNA in developing dendrites \\
$\begin{array}{l}\text { Days } \\
\text { in } \\
\text { vitro }\end{array}$ & $N$ & $\begin{array}{l}\text { Two or more } \\
\text { labeled } \\
\text { dendrites }\end{array}$ & $\begin{array}{l}\text { One labeled } \\
\text { dendrite }\end{array}$ & $\begin{array}{l}\text { No labeled } \\
\text { dendrites }\end{array}$ \\
\hline 1 & 324 & $64 \%$ & $21 \%$ & $15 \%$ \\
3 & 318 & $78 \%$ & $12 \%$ & $10 \%$ \\
5 & 215 & $99.5 \%$ & $0.5 \%$ & \\
7 & 227 & $99 \%$ & $1 \%$ & \\
11 & 180 & $100 \%$ & & \\
14 & 180 & $100 \%$ & & \\
\hline
\end{tabular}

were similar to 1 -d-old neurons (Fig. 1C) except that more (86\%) exhibited labeling over two or more minor processes. Nearly all 5 -d-old neurons (now at stage 4) displayed label in several dendrites at the end of a $6 \mathrm{hr}$ chase period. Neurons maintained in culture for 10-14 d (Fig. 1E,F) usually displayed labeling over all dendrites. These data are summarized in Table 1.

At $1 \mathrm{~d}$ in culture, axons of most neurons were labeled, indicating the presence of recently synthesized RNA (Fig. 1B). Labeling was particularly prominent over growth cones (Fig. 1B,C). Eighty-three percent of the neurons with axons exhibited axonal labeling at $1 \mathrm{~d}$ in vitro, whereas $65 \%$ had labeled axons after 3 $\mathrm{d}$ in vitro. This decrease was significant $(p<0.001)$. By $5 \mathrm{~d}$ in culture, few labeled axons could be detected; the actual number of neurons with labeled axons could not be determined because axons could not be traced to their cells of origin. It should be noted that although the same criteria for labeling were applied to axons and minor processes (more than 10 silver grains per neurite), the density of silver grains usually appeared greater over minor processes than over axons.

\section{Distribution of $r R N A$ in developing neurons}

Since newly synthesized RNA was translocated into neurites at all stages, it was of interest to determine the identity of the neuritic RNA. Analysis of neurons hybridized with an oligonucleotide probe for rRNA revealed labeling over the minor processes of most neurons maintained in culture for $1-3 \mathrm{~d}$ (Fig. $2 A, B)$. After $6 \mathrm{~d}$, nearly every neuron exhibited extensive dendritic labeling (Fig. $2 C$ ). Neurons maintained in culture for 10 d (Fig. $2 D$ ) or 14 d (Fig. $2 E$ ) had more elaborate dendritic arbors and exhibited more dendritic labeling. The proportion of neurons with one or two labeled processes is shown in Table 2. Although we have reported our data in terms of the percentage of cells with one or two or more labeled neurites, smaller amounts of rRNA were probably present in all minor processes and dendrites, but were not detectable with our method. Thus, the percentages reported are intended to provide a reflection of the range of distributions observed at each stage and the change in labeling over development.

Axonal labeling with rRNA probes was observed in $82 \%$ of the 1-d-old neurons that possessed morphologically identifiable axons. The percentage of neurons with labeled axons decreased to $54 \%$ by $3 \mathrm{~d}$ (significantly different from $1 \mathrm{~d}, p<0.0001$ ). Growth cones of axons and minor processes were often labeled 


\section{rRNA}

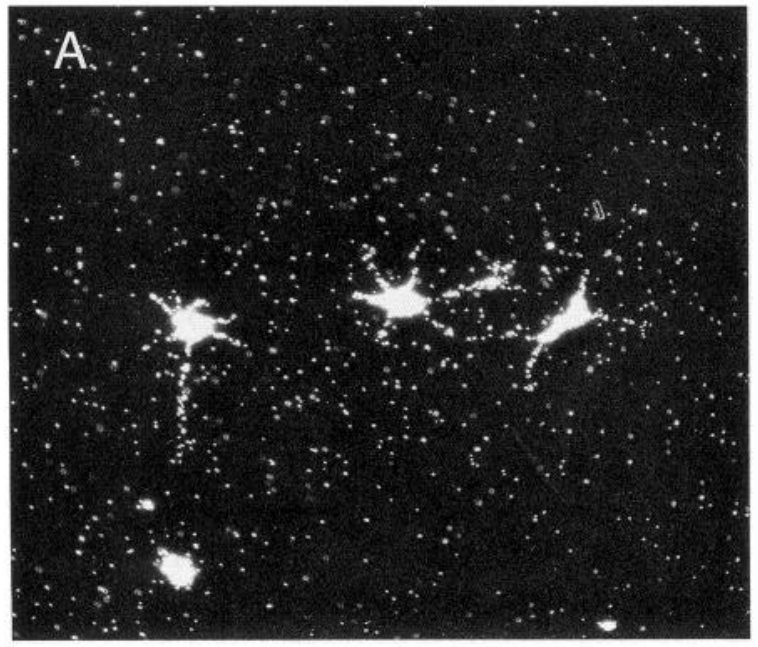

1 DIV

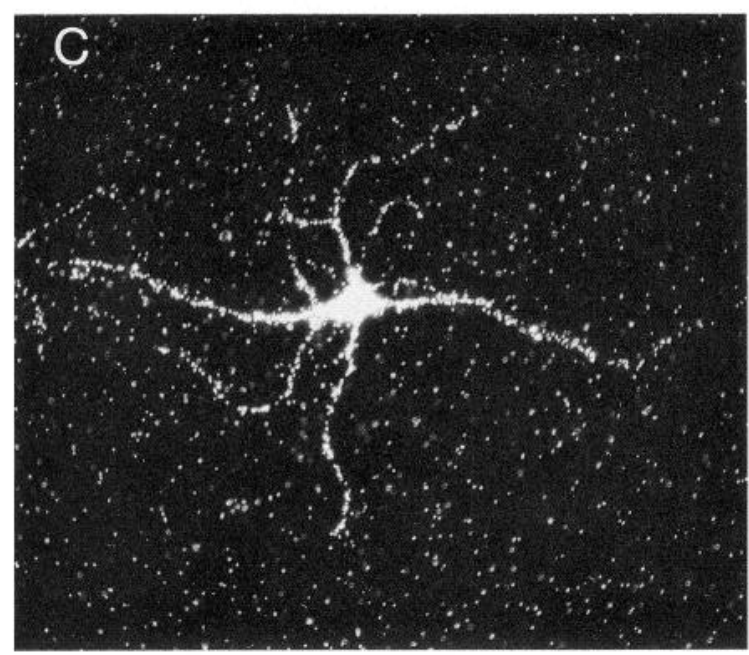

6 DIV

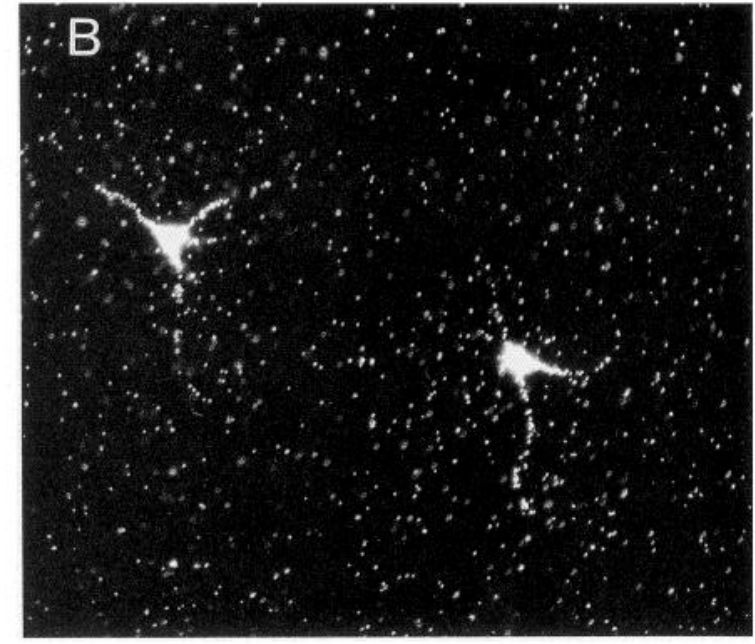

\section{DIV}

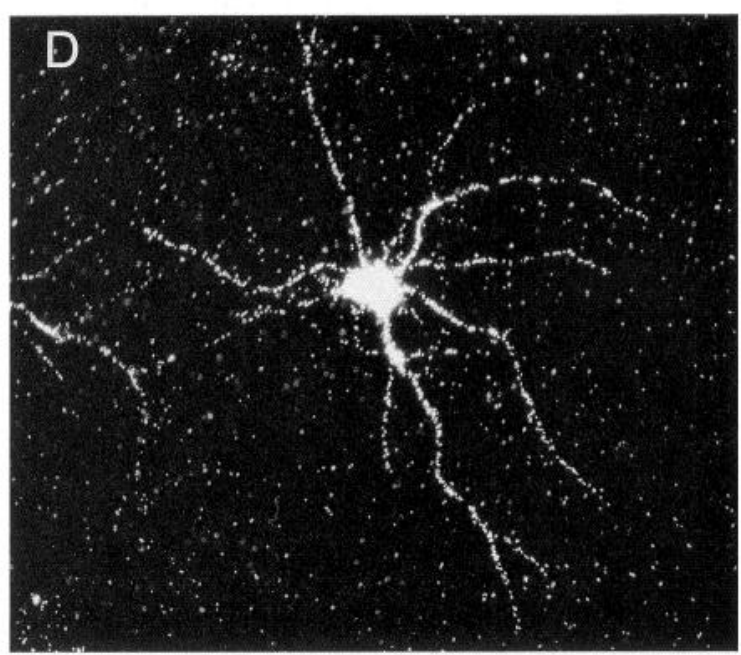

10 DIV

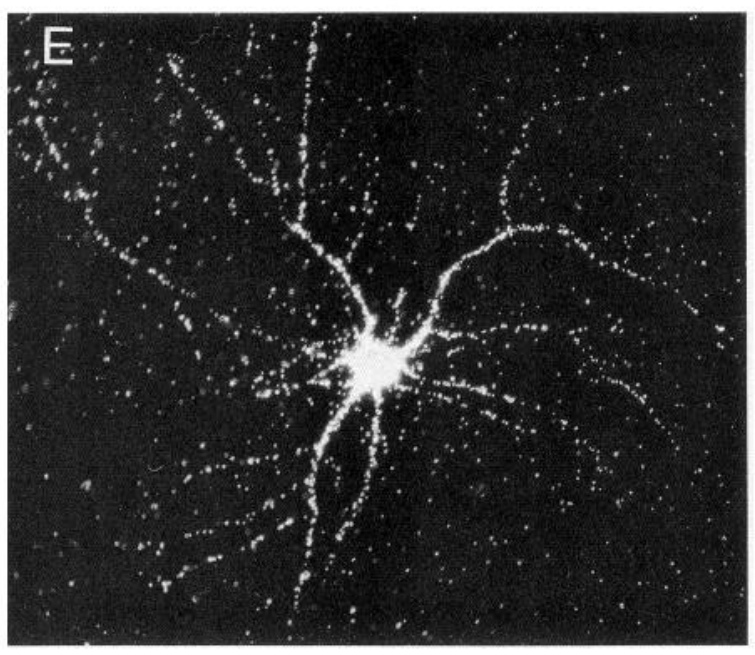

14 DIV
$50 \mu \mathrm{m}$

Figure 2. Distribution of rRNA in developing hippocampal neurons in culture. Neurons that had been maintained in culture for $1(A), 2(B), 6$ $(C), 10(D)$, or $14(E)$ d were hybridized with a ${ }^{3} \mathrm{H}$-labeled oligonucleotide probe to rRNA. Shown are dark-field photomicrographs of representative neurons from each developmental stage examined. 

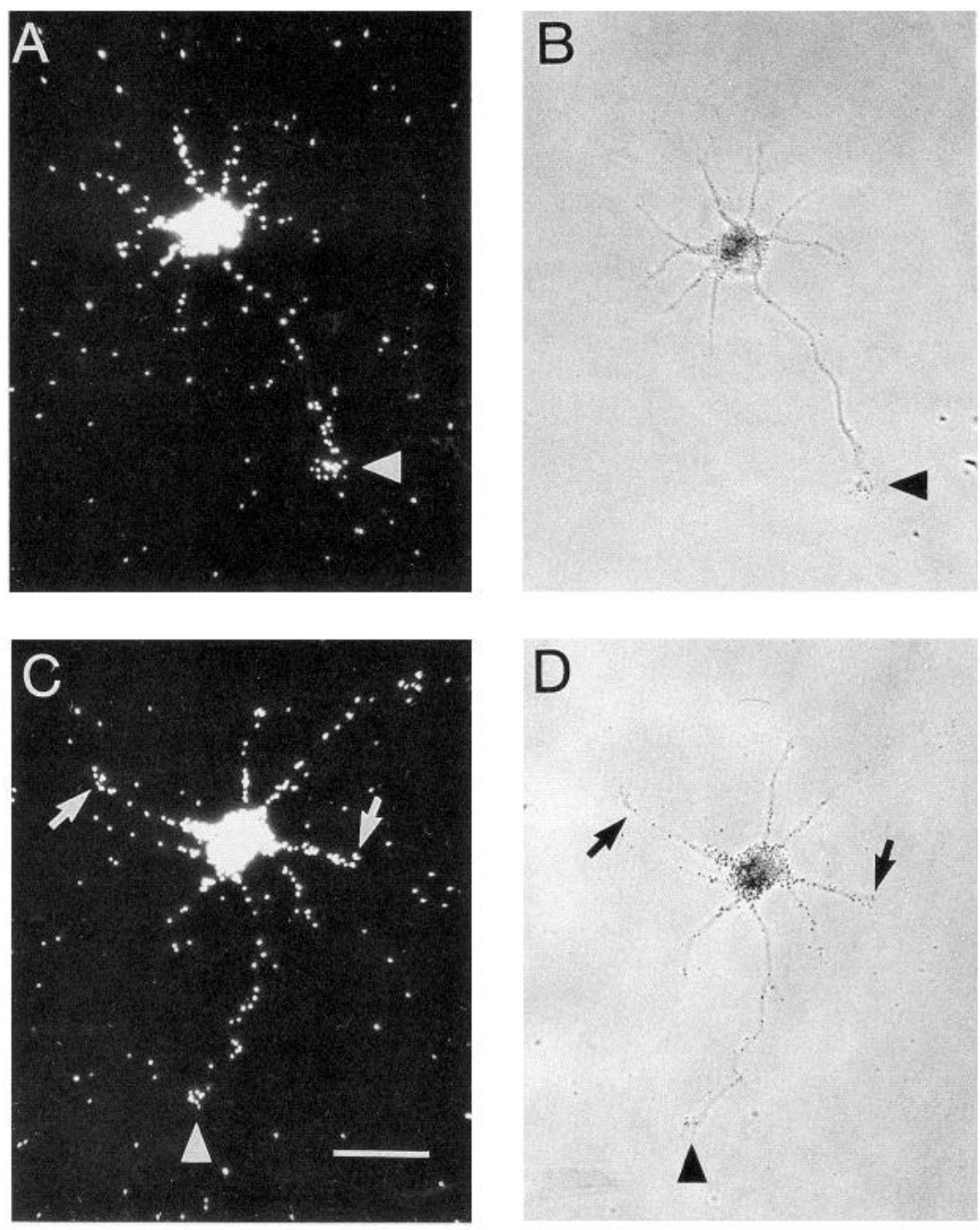

Figure 3. rRNA in growth cones of developing neurons. Dark-field and corresponding bright-field photomicrographs show neurons that had been maintained in culture for $1(A, B)$ or 2 $(C, D)$ days were hybridized with ${ }^{3} \mathrm{H}-$ labeled oligonucleotide probes for rRNA. Shown are examples of labeled growth cones of axons (arrowhead) and minor processes (arrows). Scale bar, 25 $\mu \mathrm{m}$.
(Fig. 3). Labeling of axons was only occasionally detected in mature (10-14-d-old) neurons (not shown).

\section{Distribution of polyA RNA in developing neurons}

Neurons hybridized with probes to polyA RNA were more lightly labeled than were neurons hybridized with probes for rRNA. This is not surprising, given the relative abundance of rRNA in comparison to polyA RNA. Autoradiographs of neurons hybridized with probes to polyA revealed labeling in some neurites at all time points examined (Fig. 4). Most of the neurons present in 1- or 2-d-old cultures had no labeled neurites (Fig. 4A,B). By $5 \mathrm{~d}$, about $50 \%$ of the neurons exhibited some dendritic labeling (Fig. $4 C$ ). The extent of dendritic labeling increased progressively at 10 and $14 \mathrm{~d}$. The probability of detecting polyA RNA in more than one developing dendrite was $26 \%$ at $5 \mathrm{~d}$ in culture, and $99 \%$ at 10 or $14 \mathrm{~d}$. This represents a highly significant increase $(p<0.001)$. These data are summarized in Table 3 .

A few neurons $(8 \%)$ that had been maintained in culture for $1 \mathrm{~d}$ and that had developed an axon displayed axonal labeling with the polyA probe. Labeled axons were not detected in neurons that had been maintained in culture for $5 \mathrm{~d}$ or more.

\section{Distribution of particular mRNAs in developing neurons}

Neurons maintained for $1,2,5,10$, and $14 \mathrm{~d}$ in culture and hybridized with probes for tubulin, GAP-43, and actin are depicted in Fig. 5. As is evident, each of these mRNAs was re- stricted to the cell bodies of neurons at all ages. There was no detectable hybridization to neurites with any of the probes at any of the time points examined.

The pattern of hybridization to MAP2 mRNA in neurons of different ages is illustrated in Figure 6. Levels of MAP2 mRNA were initially very low, but increased after $5 \mathrm{~d}$ in culture. At early stages the labeling that was detectable was primarily over the cell bodies (Fig. 6A). By $5 \mathrm{~d}$ in culture dendritic labeling was detectable in some neurons (Fig. $6 B$ ), and by 6-7 d in culture many neurons had labeled dendrites (Fig. $6 C$ ). Neurons maintained in culture for 10-14 d usually showed MAP2 hybridization over many, but not necessarily all dendrites (Fig. 6D,E).

The extent of dendritic labeling observed after hybridization for MAP2 appeared to be related to the overall level of labeling.

Table 3. Appearance of PolyA + RNA in developing dendrites

\begin{tabular}{lllll}
$\begin{array}{l}\text { Days } \\
\text { in } \\
\text { vitro }\end{array}$ & $N$ & $\begin{array}{l}\text { Two or more } \\
\text { labeled } \\
\text { dendrites }\end{array}$ & $\begin{array}{l}\text { One labeled } \\
\text { dendrite }\end{array}$ & $\begin{array}{l}\text { No } \\
\text { labeled } \\
\text { dendrites }\end{array}$ \\
\hline 1 & 298 & $15 \%$ & $13 \%$ & $72 \%$ \\
2 & 401 & $20 \%$ & $21 \%$ & $58 \%$ \\
5 & 167 & $26 \%$ & $25 \%$ & $49 \%$ \\
10 & 215 & $99 \%$ & $0.5 \%$ & $0.5 \%$ \\
14 & 224 & $99.5 \%$ & $0.5 \%$ & \\
\hline
\end{tabular}




\section{Poly A+ RNA}

\section{DIV}
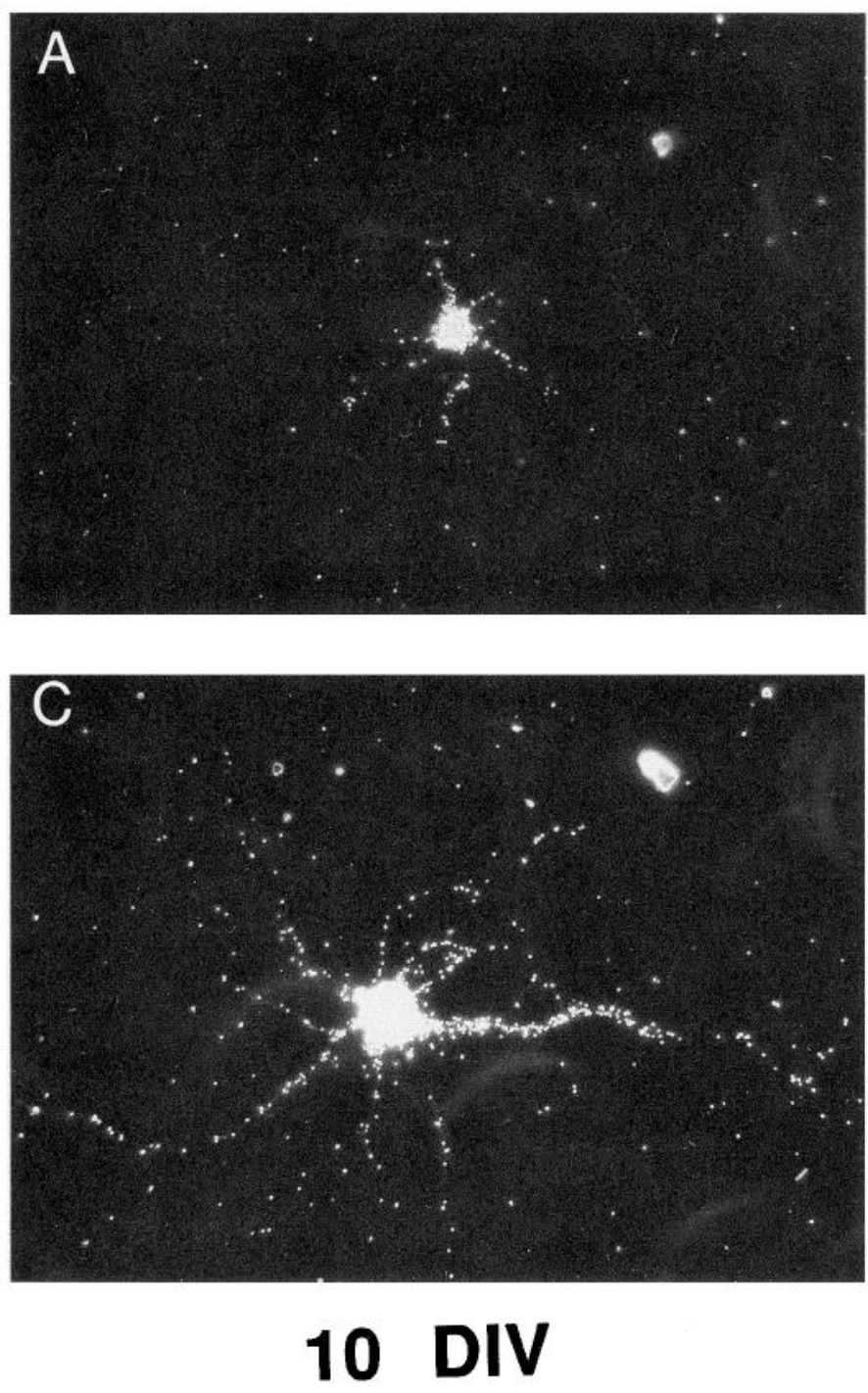

\section{DIV}
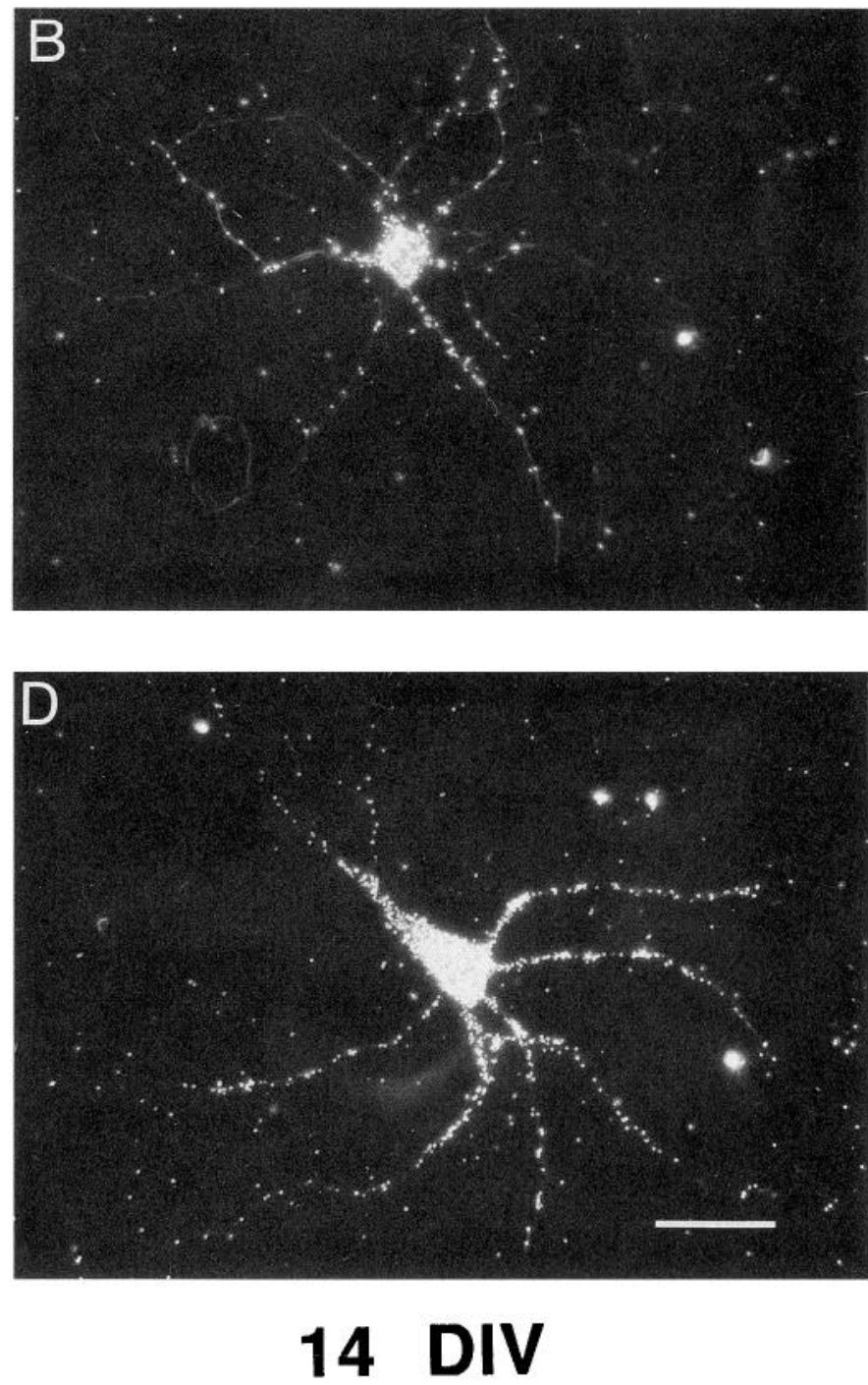

Figure 4. Distribution of polyA RNA in developing hippocampal neurons in culture. Neurons that had been maintained in culture for $1(A)$, 5 $(B), 10(C)$, or $14(D)$ days were hybridized with a ${ }^{3} \mathrm{H}$-labeled cRNA probe for polyA RNA. Shown are dark-field photomicrographs of representative neurons from each developmental stage examined. Scale bar, $50 \mu \mathrm{m}$.

In all culture preparations examined, MAP2 mRNA first appeared in dendrites between 5 and $7 \mathrm{~d}$ in culture and the percentage of neurons expressing MAP2 mRNA in one or more dendrites increased between 5 and $10 \mathrm{~d}$ in culture. Adult patterns of compartmentation were achieved by $10 \mathrm{~d}$ in culture. Longer exposure of the autoradiograms resulted in a greater proportion of labeled dendrites. In one experiment in which autoradiograms were exposed for $32 \mathrm{~d}$, the proportion of neurons with one or more MAP2-positive dendrites was $28 \%$ at $5 \mathrm{~d}$ in vitro and $83 \%$ at $14 \mathrm{~d}$ in vitro. In a different experiment, using the same MAP2 probe in which autoradiographs were exposed for $18 \mathrm{~d}$, the proportion of neurons with one or more MAP2-positive dendrites was $3 \%$ at $5 \mathrm{~d}$ in vitro and $44 \%$ at $14 \mathrm{~d}$ in vitro.

\section{Discussion}

The principal observations of the present study are as follows: (1) During the early stages of neurite outgrowth before minor processes begin to differentiate into dendrites, newly synthesized RNA is translocated into all developing neurites including developing axons. At this stage, polyA RNA and rRNA are also

Figure 5. Distribution of GAP-43, tubulin, and actin in neurons maintained in culture for 1, 5, or $14 \mathrm{~d}$. Neurons that had been maintained in culture for $1(A, D, G)$ or $5(B, E, H)$, or $14(C, F, I)$ d were hybridized with ${ }^{35}$ S-labeled cRNA probes for GAP-43 $(A-C)$, tubulin $(D-F)$, or actin $(G-I)$. Shown are dark-field photomicrographs of representative neurons from each developmental stage examined. Scale bar, $50 \mu \mathrm{m}$. 

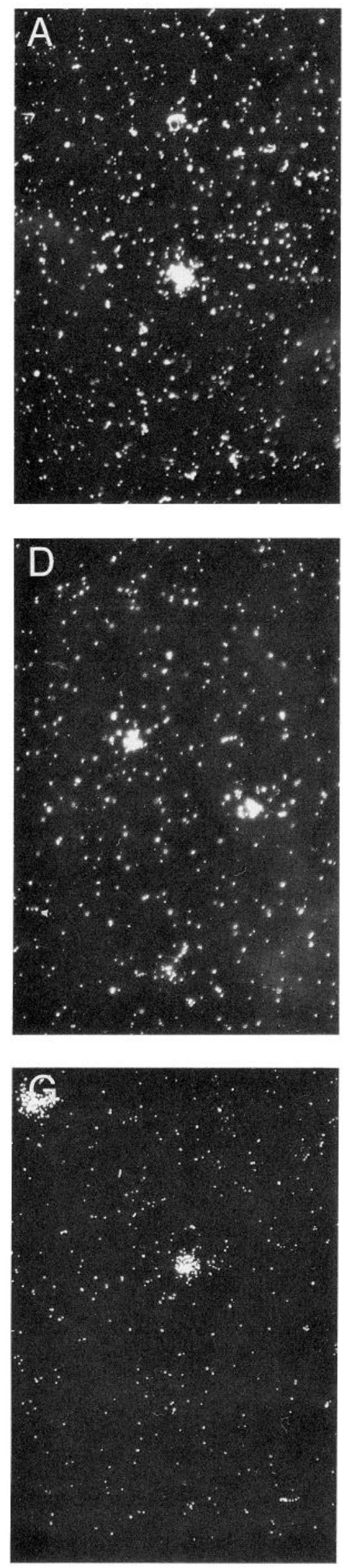
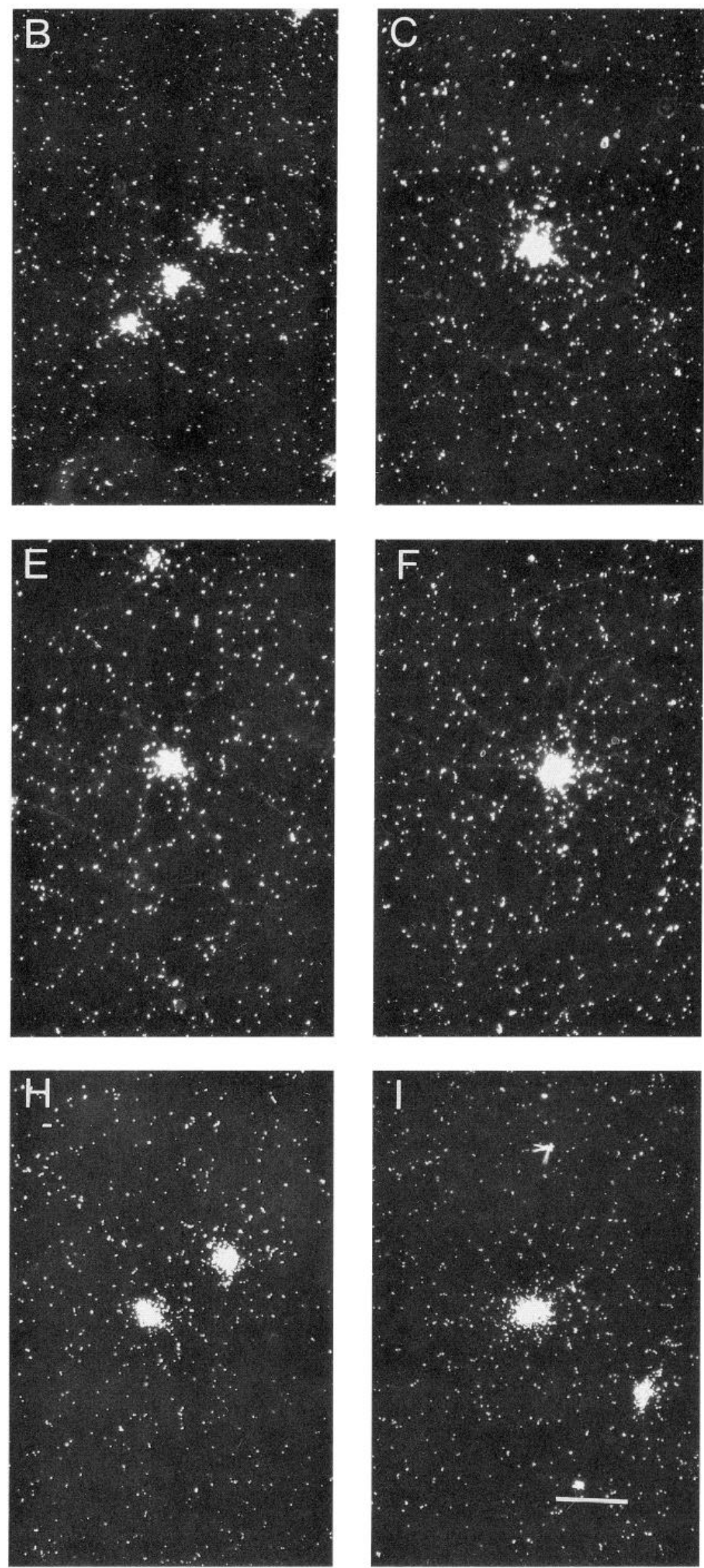


\section{MAP2 mRNA}

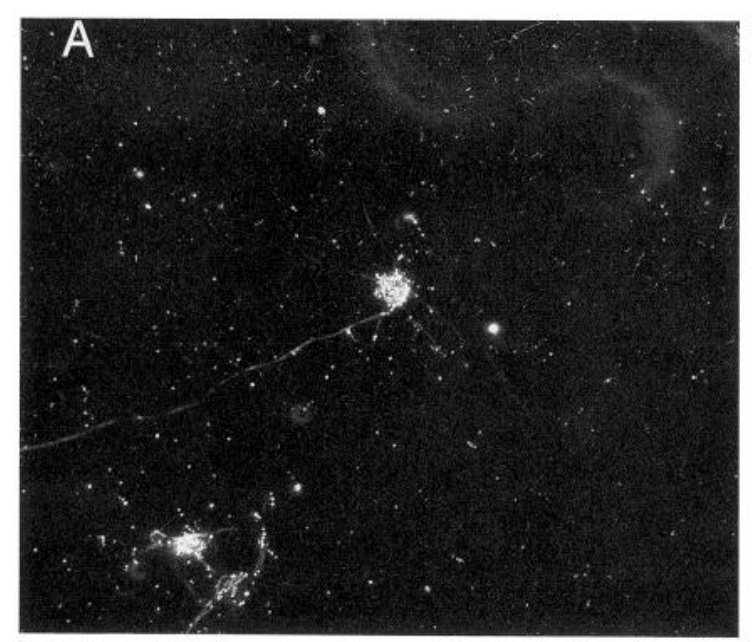

2 DIV

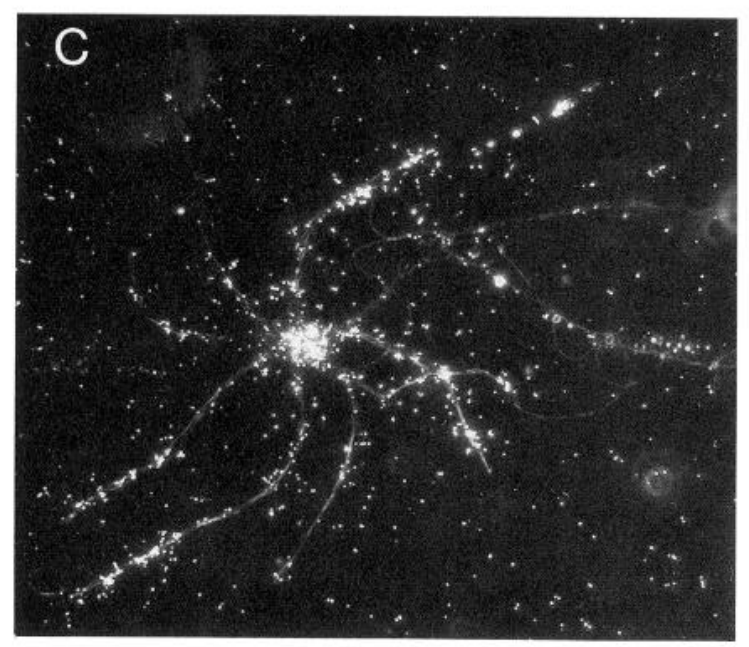

7 DIV

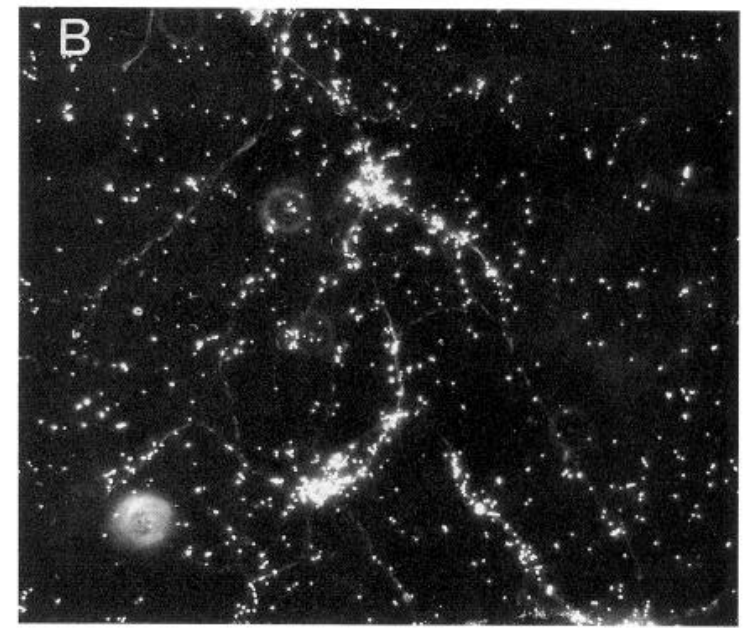

\section{DIV}

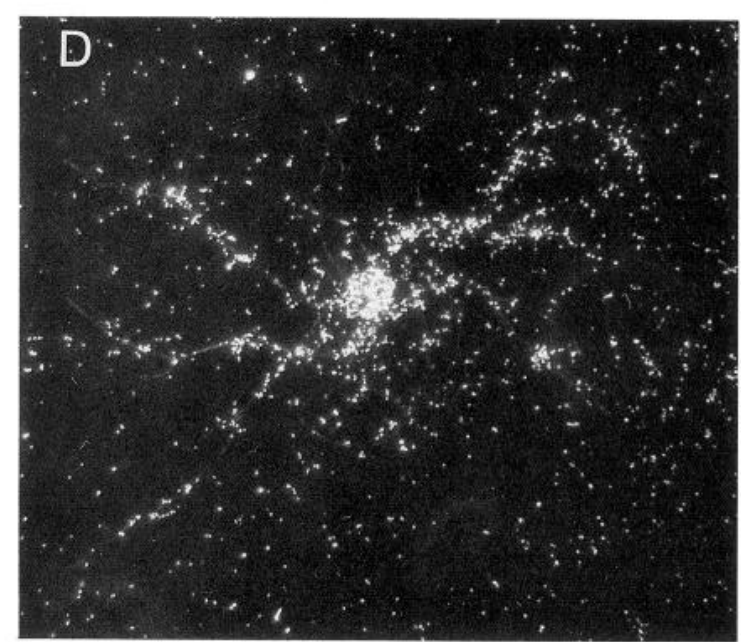

10 DIV

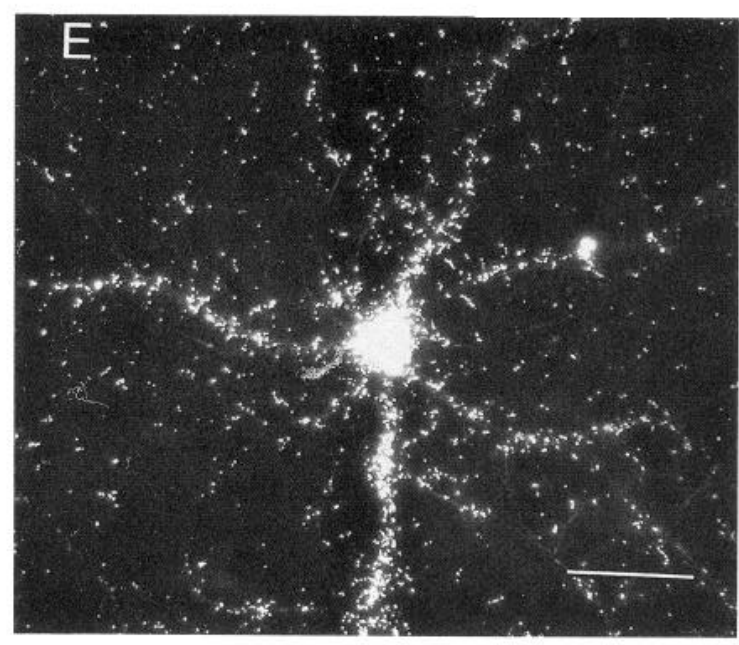


detectable in developing neurites including axons. (2) As neuronal polarity emerges and dendrites begin to assume their distinct characteristics (about $5 \mathrm{~d}$ in vitro), the translocation of newly synthesized RNA becomes selective for the dendrites, and polyA and rRNA disappear from the axons. (3) At about the same time, mRNA encoding MAP2 is first detectable in dendrites. (4) The mRNAs that are restricted to the cell bodies of mature neurons are also restricted to the cell body throughout development.

\section{The development of $R N A$ sorting mechanisms}

The fact that actin, tubulin, and GAP-43 mRNA are confined to the cell body at all developmental stages suggests that some aspects of mRNA sorting are present at the earliest stages of development. Despite the fact that newly synthesized RNA can be translocated into all neurites (including axons), and that some polyA RNA is apparently present, the mRNAs that are normally restricted to the cell body are not detectable in neurites. One cannot exclude the possibility that these mRNAs are present in developing neurites at very low levels. Whether the restriction to the cell body is absolute or not, these mRNAs have a different distribution than polyA RNA. Thus, the results indicate that mechanisms exist for restricting the distribution of mRNAs to the cell body at all developmental stages.

MAP2 mRNA was first detected in dendrites between 5 and $7 \mathrm{~d}$ in culture; this is about the time that dendrites acquire other distinguishing characteristics. During the same period, the levels of rRNA and polyA RNA also increased in dendrites. The polymerase III transcript $\mathrm{BCl}$ also first becomes detectable in the dendrites of cultured hippocampal dendrites at about the same time (Tiedge et al., 1991b). One interpretation of these results is that MAP2 mRNA is not transported into dendrites until 5$7 \mathrm{~d}$ in culture, coincident with the start of dendritic outgrowth. Alternatively, it is possible that the overall levels of MAP2 mRNA are too low before $5 \mathrm{~d}$ in vitro to permit detection of mRNA that is present in dendrites. Because of the low levels of expression of MAP2 at early stages, it cannot be determined whether the mechanisms exist for delivering particular mRNAs before about $5 \mathrm{~d}$ in vitro. In any case, there appears to be an increase in the amount of MAP2 $\mathrm{mRNA}, \mathrm{BC} 1 \mathrm{RNA}$, and polyA RNA within dendrites at the time that dendrites acquire their defining characteristics.

Even at the later stages, not all neurons exhibited labeling with probes to MAP2 mRNA over every dendrite (see also Kleiman et al., 1990). It is not possible to determine whether RNA was excluded from some dendrites, or whether our method of detecting the RNA was simply not sensitive enough to detect low levels of RNA that may have been present.

It is not clear whether the appearance of dendritic mRNA is a trigger for, or a consequence of, dendritic maturation. There are well-documented situations in which the subcellular localization of particular mRNAs contributes to cellular differentiation. For example, in Xenopus oocytes, the selective localization of a maternal mRNA termed $\mathrm{Vg} 1$, which encodes a member of the transforming growth factor- $\beta$ family of growth factors, plays an important role in the development of the animal-vegetal axis of the embryo (Melton, 1987). Similarly, in Drosophila, the mRNA encoding the transcriplion factor "bicoid" must be selectively localized in the anterior pole of the oocyte for the proper development of the anterior-posterior axis of the embryo (Frigerio et al., 1986; MacDonald and Strul, 1988). By analogy, the mRNAs that are present in dendrites could play a role in dendritic differentiation. Studies that disrupt subcellular RNA compartmentation during neuronal development, particularly during the period between 5 and $7 \mathrm{~d}$ in culture, may provide more insights into the role of RNA localization in dendritic maturation.

\section{The significance of RNA in the axons of immature neurons}

An interesting aspect of these findings is that newly synthesized RNA migrates into the axons of young neurons and that some rRNA and polyA RNA can also be detected. The probability of detecting these RNAs in axons declines as the neurons mature. Previous electron microscopic studies of cultured hippocampal neurons indicate that at 1-2 $\mathrm{d}$ in vitro, the number of polyribosomes in axons is sevenfold lower than in minor processes (Deitch and Banker, 1993). The density of silver grains following hybridization with probes to rRNA was lower over labeled axons than over minor processes but probably not by sevenfold. Although in situ hybridization may not be an accurate method for quantification of RNA levels within processes, the counts of ribosomes would predict that there should be a greater difference in labeling than was observed. It is possible that some of the rRNA in young axons is present as free rRNA or single ribosomes (which might have gone unnoticed in the electron microscopic studies), rather than in association with polysomes.

The presence of polyA RNA in the axons of immature neurons presumably reflects the presence of some mRNA species. It is possible that specific mRNAs other than the ones examined in these studics may be selcctively delivered to the axon during this period of rapid growth. In this regard, it is of interest that recent reports indicate the presence of the $\mathrm{mRNA}$ for the $\mathrm{mi}$ crotubule-associated protein tau in the initial segment of some axons of neurons in culture (Litman et al., 1993). Tau is an important component of the axonal cytoskeleton. These results suggest that local protein synthesis may play some role in the initial phase of axonal outgrowth.

The presence of certain mRNAs in young axons may explain the initially nonpolarized distribution of certain dendrite-specific proteins. For example, at early stages in the development of hippocampal neurons MAP2 protein is present in axons as well as dendrites (Caceres et al., 1986). MAP2 disappears from developing axons by the end of the first week in culture, at about the time that RNA becomes difficult to detect in axons. If some polysomes (with mRNA) were carried into the rapidly elongating axon nonselectively (at levels undetectable by in situ hybridization) it could explain the nonpolarized localization of proteins that are preferentially localized in dendrites in mature neurons.

\section{Conclusion}

Taken together with previous studies, the present results reveal that the development of neuronal polarity (i.e., the establishment of distinct axonal and somatodendritic domains) is ac- 
companied by important changes in RNA sorting and intracellular transport processes. Whatever mechanisms account for the intracellular migration of RNA disappear from axons and become more prominent in dendrites. It remains to be determined whether the development of mechanisms allowing the polarized distribution of RNA is a cause or effect of the development of other aspects of neuronal polarity.

\section{References}

Banker GA, Cowan WM (1977) Rat hippocampal neurons in dispersed cell culture. Brain Res 126:397-425.

Bartlett WP, Banker GA (1984) An electron microscopic study of the development of axons and dendrites by hippocampal neurons in culture. I. Cells which develop without intercellular contacts. J Neurosci 4:1944-1953.

Bruckenstein DA, Lein PJ, Higgins D, Fremeau R Jr (1990) Distinct spatial localizations of mRNA in cultured sympathetic neurons. Neuron $5: 809-819$.

Bruning JL, Kintz BL (1977) Computational handbook of statistics, 2d ed Glenview, II : Foresman.

Burgin KE, Waxham MN, Rickling S, Westgate SA, Mobley WC, Kelly PT (1990) In situ hybridization histochemistry of Ca/calmodulin dependent protein kinase in developing rat brain. J Neurosci 10:17881789.

Caceres A, Banker GA, Binder L (1986) Immunocytochemical localization of tubulin and microtubule-associated protein 2 during the development of hippocampal neurons in culture. J Neurosci 6:714722.

Cleveland DW, Lopata MA, MacDonald RJ, Cowan NJ, Rutter WJ, Kirschner MW (1980) Number and evolutionary conservation of alpha and beta tubulin and cytoplasmic beta and gamma actin genes using specific cloned cDNA probes. Cell 20:95-105.

Craig AM, Blackstone CD, Huganir RL, Banker G (1993) Distribution of non-NMDA glutamate receptor subunits in cultured rat hippocampal neurons: clustering of AMPA-selective subunits at postsynaptic sites on spines. Neuron 10:1055-1068.

Davis L, Banker GA, Steward O (1987) Selective dendritic transport of RNA in hippocampal neurons in culture. Nature 330:447-479.

Davis L, Burger B, Banker G, Steward O (1990) Dendritic transport: quantitative analysis of the time course of somatodendritic transport of recently synthesized RNA. J Neurosci 10:3056-3058.

Deitch J, Banker G (1993) An electron microscopic analysis of hippocampal neurons developing in culture: early stages in the emergence of polarity. J Neurosci 13:4301-4315.

Dotti CG, Sullivan CA, Banker GA (1988) The establishment of neuronal polarity by hippocampal neurons in culture. J Neurosci 8:14541468 .

Frigerio G, Burri M, Bopp D, Baumgartner S, Noll M (1986) Structure of the segmentation gene paired and the Drosophila PRD gene set as part of a gene network. Cell 47:735-746.

Garner C, Tucker R, Matus A (1988) Selective localization of messenger RNA for cytoskeletal protein MAP2 in dendrites. Nature 336: 674-677.

Goslin K, Banker G (1991) Rat hippocampal neurons in low density culture. In: Culturing nerve cells (Banker G, Goslin K, eds). Cambridge, MA: MIT Press.

Higgins GA, Lewis DA, Bahmanyar S, Goldgaber D, Gajdusek DC, Young WG, Morrison JH, Wilson MC (1988) Differential regulation of amyloid $\beta$-protein mRNA expression within hippocampal neuronal subpopulations in Alzheimer disease. Proc Natl Acad Sci USA 85: 1297-1301.

Kleiman R, Banker G, Steward O (1990) Differential subcellular localization of particular mRNAs in hippocampal neurons in culture. Neuron 5:821-830.

Kleiman R, Banker G, Steward O (in press) Subcellular distribution of rRNA and poly(A) RNA in hippocampal neurons in culture. Mol Brain Res

Lewis DA, Higgins GA, Young WG, Goldgaber D, Gajdusek DC, Wilson MC, Morrison JH (1988) Distribution of precursor amyloid $\beta$-protein messenger RNA in human cerebral cortex: relationship to ncurofibrillary tangles and ncuritic plaques. Proc Natl Acad Sci USA 85:1691-1695.

Litman P, Barg J, Rindzoonski L, Ginzburg I (1993) Subcellular localization of tau mRNA in differentiating neuronal cell culture: implications for neuronal polarity. Neuron 10:627-638.

MacDonald PM, Strul G (1988) Cis-acting sequences responsible for anterior localization of bicoid mRNA in Drosophila embryos. Nature 336:595-598.

Melton D (1987) Translocation of a localized maternal mRNA to the vegetal pole of Xenopus oocytes. Nature 328:80-82.

Monneron A, Moule Y (1966) Critical evaluation of specificity in electron microscopical radioautography in animal tissue. Exp Cell Res 56:179-193.

Perry RP (1963) Selective effects of actinomycin D on the intracellular distribution of RNA synthesis in tissue culture cells. Exp Cell Res 29: $400-406$.

Rao A, Steward O (1991) Evidence that protein constituents of postsynaptic membrane specializations are locally synthesized: analysis of proteins synthesized within synaptosomes. J Neurosci 11:28812895.

Rosenthal A, Chan SY, Henzel W, Haskell C, Kuang WJ, Chen E, Wilcox JN, Ulrich A, Goeddel DV, Routtenberg A (1987) Primary structure and mRNA localization of protein $\mathrm{Fl}$, a growth related protein kinase $\mathrm{C}$ substrate associated with synaptic plasticity. EMBO J 6:3641-3646.

Steward $O$ (1983) Polyribosomes at the base of dendritic spines of central nervous system neurons: their possible role in synapse construction and modification. Cold Spring Harbor Symp Quant Biol 48: $745-759$.

Steward O, Banker GA (1992) Getting the message from the gene to the synapse: sorting and intracellular transport of RNA in neurons. Trends Neurosci 15:180-186.

Steward O, Falk PM (1986) Protein synthetic machinery at postsynaptic sites during synaptogenesis; a quantitative study of the association between polyribosomes and developing synapses. J Neurosci $6: 412-423$

Steward O, Levy WB (1982) Preferential localization of polyribosomes under the base of dendritic spines in granule cells of the dentate gyrus. J Neurosci 2:284-291.

Strong MJ, Svedmyr A, Gajdusek DC, Garruto RM (1990) The temporal expression of amyloid precursor protein $\mathrm{mRNA}$ in vitro in dissociated hippocampal neuron cultures. Exp Neurol 109:171-179.

Tiedge H, Fremeau RT Jr, Weinstock PH, Arancio O, Brosius J (1991a) Dendritic location of neural BC1 RNA. Proc Natl Acad Sci USA 88: 2093-2097.

Ticdgc H, Banker G, Brosius J (1991b) Expression of BC1 RNA in developing hippocampal neurons in culture. Soc Neurosci Abstr 17: 215.6 .

Young WS III (1989) Simultaneous use of digoxigenin and radiolabeled oligodeoxyribonucleotide probes for hybridization histochemistry. Neuropeptides 13:271-275. 